\title{
Reduced fetal growth rate and increased risk of death from ischaemic heart disease: cohort study of 15000 Swedish men and women born 1915-29
}

\author{
David A Leon, Hans O Lithell, Denny Vågerö, Ilona Koupilová, Rawya Mohsen, Lars Berglund, \\ Ulla-Britt Lithell, Paul M McKeigue
}

\begin{abstract}
Objective: To establish whether fetal growth rate (as distinct from size at birth) is associated with mortality from ischaemic heart disease.

Design: Cohort study based on uniquely detailed obstetric records with $97 \%$ follow up over the entire life course and linkage to census data in adult life. Subjects: All 14611 babies delivered at the Uppsala Academic Hospital, Sweden, during 1915-29 followed up to end of 1995 .

Main outcome measures: Mortality from ischaemic heart disease and other causes.

Results: Cardiovascular disease showed an inverse association with birth weight for both men and women, although this was significant only for men. In men a $1000 \mathrm{~g}$ increase in birth weight was associated with a proportional reduction in the rate of ischaemic heart disease of 0.77 (95\% confidence interval 0.67 to 0.90). Adjustment for socioeconomic circumstances at birth and in adult life led to slight attenuation of this effect. Relative to the lowest fourth of birth weight for gestational age, mortality from ischaemic heart disease in men in the second, third, and fourth fourths was 0.81 (0.66 to 0.98$), 0.63$ (0.50 to 0.78 ), and 0.67 (0.54 to 0.82 ), respectively. The inclusion of birth weight per se and birth weight for gestational age in the same model strengthened the association with birth weight for gestational age but removed the association with birth weight.

Conclusion: This study provides by far the most persuasive evidence of a real association between size at birth and mortality from ischaemic heart disease in men, which cannot be explained by methodological artefact or socioeconomic confounding. It strongly suggests that it is variation in fetal growth rate rather than size at birth that is aetiologically important.
\end{abstract}

\section{Introduction}

In 1989 the first of a series of papers was published from a cohort study of men and women born in Hertfordshire in the 1920s and 1930s which suggested that cardiovascular disease, ischaemic heart disease in particular, was inversely associated with birth weight. ${ }^{12}$ Since then this association has been confirmed in cohorts studies from a range of countries, ${ }^{3-7}$ as reviewed elsewhere. ${ }^{8}$ Only one study, from Gothenburg, failed to find evidence of an inverse association. ${ }^{9}$

Selection bias has been a major concern of critics who have questioned the validity of these findings. ${ }^{10}{ }^{11}$ In the Hertfordshire study, for example, results are based on the follow up of less than half of all those who made up the original birth cohort. A second concern is that the association between size at birth and mortality in adult life may be due to socioeconomic confounding. ${ }^{10-12}$ Reduced size at birth may simply be a marker for poor maternal socioeconomic circumstances that predict relative deprivation of the offspring in adult life, which leads in turn to an increased risk of ischaemic heart disease. Only two previous studies have explicitly examined this issue. ${ }^{56}$

The quality and completeness of the information on size at birth in previous studies varies and is not optimal in any. Most use historical obstetric records as the source of information on size at birth, although two used self reported birth weights. ${ }^{5}$ Ponderal index has been analysed in only two studies, both of which found it to be inversely associated with cardiovascular mortality. ${ }^{3}$

Only three studies have included data on gestational age, each using it simply to restrict analyses to term births. ${ }^{367}$ There has been no systematic attempt to examine whether it is the rate of fetal growth that underlies the association of size at birth with cardiovascular mortality.

We report the results of an almost complete follow up in a cohort of all people born in Uppsala Academic Hospital in 1915-29. It contains within it 600 subjects who were part of the smaller Uppsala study of 50 year old men. ${ }^{13-16}$ This new cohort has almost complete data on a wide range of dimensions at birth, gestational age, and maternal characteristics. It contains extensive information on socioeconomic circumstances of adult study members. Because of these unique features our analyses have been able to deal with all of the important shortcomings of previous studies.

\section{Methods}

The historical cohort was based on all 14611 births in Uppsala Academic Hospital in 1915-29. Of these, 6690 were to women resident in the city of Uppsala and 4001 were to women from parishes less than $20 \mathrm{~km}$ from Uppsala. The remainder were births to women living further away, many from places with direct rail links to Uppsala. The cohort covers over $75 \%$ of all births in 1915-29 to residents of Uppsala city and 50\% of all births to residents of parishes $<20 \mathrm{~km}$ from Uppsala.

\section{Data abstracted}

Sequentially numbered obstetric records for each delivery during this period have been kept in bound volumes. Key variables abstracted included maternal parity, age, marital status, date of last menstrual period, birth weight, birth length, placental weight, child's sex, and multiplicity. Complete information on all these variables was available for $96 \%$ of subjects. Parental occupation was used to allocate each birth to one of seven social classes, ${ }^{17}$ plus a residual group for those for whom parental occupation was not stated (3\%).

\author{
Department of \\ Epidemiology and \\ Population Health, \\ London School of \\ Hygiene and \\ Tropical Medicine, \\ London \\ WC1E 7HT \\ David A Leon, \\ senior lecturer \\ Ilona Koupilová, \\ lecturer \\ Paul M McKeigue, \\ reader \\ Institute of \\ Geriatrics, \\ University of \\ Uppsala, S-751 25 \\ Uppsala, Sweden \\ Hans O Lithell, \\ professor \\ Rawya Mohsen, \\ programmer \\ Lars Berglund, \\ statistician \\ Ulla-Britt Lithell, \\ assistant professor \\ Department of \\ Sociology, \\ Stockholm \\ University, S-106 91 \\ Stockholm, Sweden \\ Denny Vågerö, \\ professor \\ Correspondence to: \\ Dr Leon \\ dleon@lshtm.ac.uk
}

BMJ 1998;317:241-5 
Table 1 Perinatal characteristics of singleton, live born, traced children born at Uppsala Academic Hospital 1915-29 at birth and at age 1, 15, and 65 years. Numbers in parentheses are number of subjects

\begin{tabular}{lcccc} 
Characteristic & Birth & Age 1 year & Age 15 years & Age 65 years \\
\hline Mean birth weight $(\mathrm{g})$ & $3429(13 \mathrm{363})$ & $3460(12537)$ & $3463(12062)$ & $3461(9 \mathrm{967})$ \\
\hline Proportion $(\%)<2500 \mathrm{~g}$ & 4.7 & 3.3 & 3.2 & 3.2 \\
\hline Median gestation (days) & $280(12997)$ & $281(12194)$ & $281(11738)$ & $281(9706)$ \\
\hline $\begin{array}{l}\text { Proportion }(\%) \text { born }<37 \\
\text { weeks' gestation }\end{array}$ & 8.6 & 7.3 & 7.2 & 7.1 \\
\hline Mean birth length $(\mathrm{cm})$ & $50.7(13328)$ & $50.9(12502)$ & $50.9(12027)$ & $50.8(9939)$ \\
\hline Mean ponderal index $\left(\mathrm{kg} / \mathrm{m}^{3}\right)$ & $26.1(13321)$ & $26.2(12501)$ & $26.2(12062)$ & $26.3(9938)$ \\
\hline
\end{tabular}

Follow up entailed tracing each subject through the statutory system of parish archives that recorded all births, deaths, and changes in residence. For almost all of those surviving until the early 1950 s we found personal identity numbers that were introduced around this time. Information on deaths and emigrations held on computerised data files from this point onwards were linked to study members by using this number.

Underlying cause of death was available from nationally collated and centrally coded computerised data from 1952. These data were coded according to the revision of the international classification of diseases in force at the time of death. To ensure that cause of death categories were relatively homogenous, cause specific analyses were restricted to deaths occurring after the introduction in Sweden of ICD-7 (international classification of diseases, 7th revision) in 1958.

Information on access to cars, marital status, occupation, education, and income was obtained from the 1960 and 1970 censuses. Of those known to be alive on the date of each census, more than $99 \%$ were successfully linked. Analyses in which we controlled for these socioeconomic factors were thus restricted to deaths occurring after the 1970 census.

\section{Statistical analysis}

We used Cox's proportional hazards model in the STATA statistical package to analyse the mortality data. ${ }^{18}$ Subjects exited from risk on their date of first emigration, death, or end of follow up (31 December 1995), whichever was soonest. In all models the time dimension was defined as age. Three periods of birth were included (1915-9, 1920-4, and 1925-9). Birth weight (recorded to the nearest $10 \mathrm{~g}$ with some heaping at $50 \mathrm{~g}$ and $100 \mathrm{~g}$ ) was classified into four categories with the same cut offs as used in our previous work on blood pressure and birth weight. ${ }^{13}$ Ponderal index was calculated in units of $\mathrm{kg} / \mathrm{m}^{3}$, with birth length recorded to the nearest $\mathrm{cm}$. Gestational age in days was calculated by using date of last menstrual period. Birth weight for gestational age for each subject was defined as a sex specific $\mathrm{z}$ score calculated for each week of gestation for the $99 \%$ of births with gestations of 30 weeks or more. $\mathrm{Z}$ scores were not calculated for births with shorter gestations because of statistical imprecision arising from small numbers. Trend tests for birth weight, birth weight for gestational age, and ponderal index were calculated on the basis of the continuous variables. Significance was defined as $\mathrm{P}<0.05$.

\section{Results}

Records were identified for 14611 deliveries that had occurred from 1915 to 1929 in the Uppsala Academic Hospital, of which 418 were stillbirths. Of the live births, 14026 were singletons; 382 (2.7\%) children could not be traced; and 911 died in their first year of life. Of the total number of traced live singleton births 7012 were male and $6351 \mathrm{female}$. Among the traced births the perinatal mortality in the cohort was 50 per 1000 live births and stillbirths, and the neonatal and postneonatal rates were 30 and 36 per 1000 live births, respectively. Of the 13282 subjects surviving to the age of 1 year, by the end of follow up (31 December 1995) 197 had emigrated, 4087 had died, and 8616 were still alive. The perinatal characteristics of the singleton live born traced subjects are shown in table 1 along with the characteristics of those who survived to age 1,15 , and 65 years.

The association of birth weight with mortality at different ages is shown in table 2 . The powerful association between low birth weight and infant mortality was evident for both sexes. A more continuous inverse association of mortality across the four birthweight categories was evident in children (ages 1-14 years). No systematic association was apparent at working ages, while at age $\geqslant 65$ years among men there was a suggestion of a reverse $\mathrm{J}$ shaped association of birth weight with mortality.

The proportional changes in adult mortality from specific causes of death associated with an increase in birth weight of $1000 \mathrm{~g}$ are shown in table 3. Mortality from all neoplasms increased slightly with birth weight, although this was not significant. For all other causes, except respiratory disease, mortality decreased as birth

Table 2 Rate ratios (95\% confidence interval) for all cause mortality $1915-95$ by birth weight, sex, and age at risk for all traced singleton live births delivered at Uppsala Academic Hospital, 1915-29

\begin{tabular}{|c|c|c|c|c|c|c|c|c|c|}
\hline \multirow[b]{3}{*}{$\begin{array}{l}\text { Age at risk } \\
\text { (years) }\end{array}$} & \multicolumn{8}{|c|}{ Birth weight } & \multirow[b]{3}{*}{$\begin{array}{l}P \text { value } \\
\text { for trend }\end{array}$} \\
\hline & \multicolumn{2}{|c|}{$<3250 \mathrm{~g}$} & \multicolumn{2}{|r|}{$3250-3749 \mathrm{~g}$} & \multicolumn{2}{|r|}{$3750-4249 \mathrm{~g}$} & \multicolumn{2}{|r|}{$\geqslant 4250 \mathrm{~g}$} & \\
\hline & $\begin{array}{c}\text { No of } \\
\text { deaths }\end{array}$ & $\begin{array}{l}\text { Rate ratio } \\
(95 \% \mathrm{Cl})\end{array}$ & $\begin{array}{l}\text { No of } \\
\text { deaths }\end{array}$ & $\begin{array}{l}\text { Rate ratio } \\
(95 \% \mathrm{Cl})\end{array}$ & $\begin{array}{c}\text { No of } \\
\text { deaths }\end{array}$ & $\begin{array}{c}\text { Rate ratio } \\
(95 \% \mathrm{Cl})\end{array}$ & $\begin{array}{c}\text { No of } \\
\text { deaths }\end{array}$ & $\begin{array}{l}\text { Rate ratio } \\
(95 \% \mathrm{Cl})\end{array}$ & \\
\hline \multicolumn{10}{|l|}{ Males } \\
\hline$<1$ & 259 & 1.00 & 114 & $0.31(0.25$ to 0.39$)$ & 78 & $0.35(0.27$ to 0.45$)$ & 30 & 0.45 (0.31 to 0.65$)$ & $<0.001$ \\
\hline $1-14$ & 81 & 1.00 & 102 & 0.85 (0.64 to 1.14$)$ & 45 & 0.62 (0.43 to 0.89$)$ & 12 & $0.54(0.30$ to 1.00$)$ & $<0.001$ \\
\hline $15-64$ & 348 & 1.00 & 491 & 0.94 (0.82 to 1.08$)$ & 310 & 0.98 (0.84 to 1.15$)$ & 96 & 1.00 (0.81 to 1.26$)$ & 0.933 \\
\hline$\geqslant 65$ & 299 & 1.00 & 412 & 0.89 (0.77 to 1.03$)$ & 226 & 0.82 (0.69 to 0.97$)$ & 75 & 0.90 (0.70 to 1.15$)$ & 0.005 \\
\hline \multicolumn{10}{|l|}{ Females } \\
\hline$<1$ & 216 & 1.00 & 86 & $0.37(0.29$ to 0.47$)$ & 35 & $0.32(0.22$ to 0.45$)$ & 8 & 0.33 (0.16 to 0.66$)$ & $<0.001$ \\
\hline $1-14$ & 98 & 1.00 & 72 & 0.64 (0.47 to 0.87$)$ & 35 & 0.67 (0.46 to 0.99$)$ & 7 & $0.58(0.27$ to 1.25$)$ & 0.003 \\
\hline $15-64$ & 243 & 1.00 & 286 & 1.04 (0.87 to 1.23$)$ & 128 & 0.99 (0.80 to 1.22$)$ & 33 & 1.13 (0.78 to 1.62$)$ & 0.958 \\
\hline$\geqslant 65$ & 204 & 1.00 & 236 & 0.99 (0.82 to 1.19$)$ & 102 & 0.93 (0.73 to 1.18$)$ & 27 & 0.98 (0.65 to 1.47$)$ & 0.586 \\
\hline
\end{tabular}


Table 3 Mortality 1958-95 associated with $1000 \mathrm{~g}$ increase in birth weight by cause of death for all traced singleton live births delivered at Uppsala Academic Hospital, 1915-29

\begin{tabular}{|c|c|c|c|c|c|}
\hline \multirow[b]{2}{*}{ Cause of death } & \multirow[b]{2}{*}{ ICD-9 code } & \multicolumn{2}{|c|}{ Men } & \multicolumn{2}{|c|}{ Women } \\
\hline & & No of deaths & Rate ratio* $(95 \% \mathrm{CI})$ & No of deaths & Rate ratio* $(95 \% \mathrm{CI})$ \\
\hline All causes & $0-999$ & 2069 & $0.92(0.84$ to 1.00$)$ & 1129 & 0.95 (0.84 to 1.07$)$ \\
\hline All neoplasms & $140-208 ; 238.4 ; 289.8$ & 599 & $1.13(0.96$ to 1.33$)$ & 480 & 1.04 (0.87 to 1.24$)$ \\
\hline Circulatory disease: & $390-459$ & 938 & $0.80(0.71$ to 0.91$)$ & 375 & 0.85 (0.70 to 1.05$)$ \\
\hline Ischaemic heart disease & $410-414$ & 679 & 0.77 (0.67 to 0.90$)$ & 187 & $0.83(0.62$ to 1.10$)$ \\
\hline Cerebrovascular disease & $430-438$ & 113 & 0.71 (0.49 to 1.03$)$ & 105 & $0.84(0.57$ to 1.24$)$ \\
\hline Respiratory disease & $460-519$ & 89 & $1.25(0.83$ to 1.90$)$ & 44 & 1.25 (0.69 to 2.27$)$ \\
\hline Accidents and violence & $800-999$ & 178 & 0.98 (0.74 to 1.32$)$ & 73 & 0.89 (0.57 to 1.41$)$ \\
\hline Other causes & Remainder & 265 & $0.79(0.63$ to 1.01$)$ & 157 & $0.88(0.64$ to 1.20$)$ \\
\hline
\end{tabular}

${ }^{*}$ Adjusted for period of birth as a three-level categorical variable (1915-9, 1920-4, 1925-9).

Table 4 Rate ratios (95\% confidence interval) for mortality from ischaemic heart disease 1970-95 by birth weight adjusted for socioeconomic circumstances for all traced singleton live male births at Uppsala Academic Hospital, 1915-29

\begin{tabular}{|c|c|c|c|c|c|c|}
\hline \multirow[b]{2}{*}{ Adjustments* } & \multicolumn{4}{|c|}{ Birth weight } & \multirow[b]{2}{*}{$\begin{array}{l}P \text { value for } \\
\text { trend }\end{array}$} & \multirow[b]{2}{*}{$\begin{array}{l}\text { Rate ratios per } 1000 \mathrm{~g} \\
\text { increase in birth weight }\end{array}$} \\
\hline & $\begin{array}{l}<3250 \mathrm{~g} \\
(\mathrm{n}=202 \mathrm{t})\end{array}$ & $\begin{array}{c}3250-3749 \mathrm{~g} \\
(\mathrm{n}=261 \dagger)\end{array}$ & $\begin{array}{c}3750-4249 \mathrm{~g} \\
(\mathrm{n}=120 \dagger)\end{array}$ & $\begin{array}{l}\geqslant 4250 \mathrm{~g} \\
(\mathrm{n}=39 \dagger)\end{array}$ & & \\
\hline Crude & 1.00 & 0.83 (0.69 to 1.00$)$ & 0.65 (0.52 to 0.81$)$ & 0.69 (0.49 to 0.97$)$ & 0.001 & $0.77(0.66$ to 0.90$)$ \\
\hline At birth $\ddagger$ & 1.00 & 0.85 (0.71 to 1.02$)$ & 0.67 (0.53 to 0.84$)$ & $0.72(0.51$ to 1.02$)$ & 0.005 & 0.80 (0.68 to 0.93$)$ \\
\hline At 1960 and 1970 census§ & 1.00 & 0.86 (0.72 to 1.04$)$ & 0.67 (0.53 to 0.84$)$ & $0.72(0.51$ to 1.01$)$ & 0.006 & 0.80 (0.69 to 0.94$)$ \\
\hline At birth $\ddagger$ and 1960 and 1970 census§ & 1.00 & $0.87(0.72$ to 1.04$)$ & $0.68(0.54$ to 0.86$)$ & $0.74(0.53$ to 1.05$)$ & 0.012 & $0.82(0.70$ to 0.96$)$ \\
\hline
\end{tabular}

*All rate ratios adjusted for period of birth as a three-level categorical variable (1915-9, 1920-4, 1925-9).

†Number of deaths from ischaemic heart disease.

tMaternal marital status, parental social class.

$\S 0$ ccupational status at 1960 census; duration of education and earned income at 1970 census plus household car ownership at 1960 and 1970 censuses.

weight increased. The largest proportional effects among men and women were for ischaemic heart disease and cerebrovascular disease, although only ischaemic heart disease among men showed a significant association.

The subjects born to parents in the manual social classes and those born to single mothers had increased rates of infant mortality and reduced size at birth. ${ }^{19}$ Mortality from ischaemic heart disease showed significant associations $(\mathrm{P}<0.05)$ with occupational status at the 1960 census, duration of education and individual earned income at the 1970 census, and household car ownership at the 1960 and 1970 censuses; mortality increased as occupational status, educational level, income, and car ownership declined (not shown). Adjustment for socioeconomic circumstances at birth and in adult life led to only a small reduction in the strength of the association between birth weight and mortality from ischaemic heart disease, which remained significant (table 4).

Birth weight is a function of gestational age at delivery and of fetal growth rate. In our data gestational age itself was not associated with mortality from ischaemic heart disease (not shown). Table 5 shows the strength of the association of mortality from ischaemic heart disease and fetal growth rate (measured as birth weight for gestational age $\mathrm{z}$ scores) and compares it with the strength of association with birth weight per se. To make the effects comparable we analysed fourths of birth weight and birth weight for gestational age.

The crude effects of birth weight and birth weight for gestational age were broadly similar, and both were highly significant (table 5).We were able, however, to separate the effect of birth weight per se from that of fetal growth rate by adjusting each for the effect of the other. When we did this, as shown in the final column of table 5, the effect of birth weight on mortality from ischaemic heart disease was almost entirely eliminated, while the effect of birth weight for gestational age was slightly strengthened. We therefore concluded that it is rate of fetal growth that underlies the association of birth weight with mortality from ischaemic heart disease.

Ponderal index $\left(\mathrm{kg} / \mathrm{m}^{3}\right)$ showed a significant inverse association with mortality from ischaemic heart disease in men $(\mathrm{P}=0.002)$. Among traced singleton births, the rate ratio relative to those with a ponderal index of $<25$ was 0.86 (95\% confidence interval 0.72 to 1.04$), 0.73$ (0.59 to 0.90$)$, and 0.76 (0.59 to 1.00$)$ for ponderal index categories of 25.0-26.9, 27.0-28.9, and $\geqslant 29.0$, respectively. After simultaneous adjustment for birth weight for gestational age, however, the effect of ponderal index was much attenuated and no longer significant $(\mathrm{P}=0.19)$. The adjusted rate ratios relative to the lowest category of ponderal index were $0.93(0.77$ to 1.13 ), 0.83 (0.66 to 1.05 ), and 0.90 (0.68 to 1.20 ).

Table 5 Rate ratios* ( $95 \%$ confidence interval) for mortality from ischaemic heart disease 1958-95 by fourths of birth weight and birth weight for gestational age for all traced singleton live male births at Uppsala Academic Hospital, 1915-29

\begin{tabular}{|c|c|c|c|c|}
\hline $\begin{array}{l}\text { Fourth } \\
\text { (No of deaths) }\end{array}$ & $\begin{array}{l}\text { Mean birth } \\
\text { weight }(g)\end{array}$ & $\begin{array}{l}\text { Range of birth } \\
\text { weight }(g)\end{array}$ & $\begin{array}{c}\text { Crude rate ratio } \\
(95 \% \mathrm{Cl})\end{array}$ & $\begin{array}{l}\text { Mutually adjusted rate } \\
\text { ratio }(95 \% \mathrm{Cl})\end{array}$ \\
\hline \multicolumn{5}{|l|}{ Birth weight } \\
\hline 1st $(n=203)$ & 2899 & 1080 to 3210 & 1.00 & 1.00 \\
\hline 2nd $(n=173)$ & 3381 & 3220 to 3530 & $0.83(0.67$ to 1.01$)$ & 0.98 (0.76 to 1.27$)$ \\
\hline 3rd $(n=152)$ & 3686 & 3535 to 3850 & $0.73(0.59$ to 0.90$)$ & $1.05(0.75$ to 1.46$)$ \\
\hline 4th $(n=133)$ & 4161 & 3855 to 5300 & $0.68(0.54$ to 0.84$)$ & 0.98 (0.63 to 1.52$)$ \\
\hline$P$ value for trend & & & 0.001 & 0.164 \\
\hline \multicolumn{5}{|c|}{ Birth weight for gestational age } \\
\hline 1st $(n=207)$ & 2949 & 1080 to 3530 & 1.00 & 1.00 \\
\hline 2nd $(n=183)$ & 3380 & 2230 to 3790 & 0.81 (0.66 to 0.98$)$ & 0.80 (0.62 to 1.04$)$ \\
\hline 3rd $(n=127)$ & 3664 & 2700 to 4050 & $0.63(0.50$ to 0.78$)$ & $0.61(0.43$ to 0.86$)$ \\
\hline 4th $(n=144)$ & 4113 & 3040 to 5300 & 0.67 (0.54 to 0.82$)$ & 0.67 (0.43 to 1.02$)$ \\
\hline$P$ value for trend & & & $<0.001$ & 0.003 \\
\hline
\end{tabular}

*Adjusted for period of birth as a three-level categorical variable (1915-9, 1920-4, 1925-9). 
There was no evidence of any association of placental weight with mortality from ischaemic heart disease (not shown).

\section{Discussion}

We have confirmed that among men mortality from ischaemic heart disease declines as birth weight increases. Similar inverse associations were evident among women and for mortality from cerebrovascular disease in both sexes, although these associations were not significant. Other causes of death showed less pronounced inverse or weak positive associations with birth weight.

\section{Strengths of data}

A unique strength of our evidence from Uppsala is that we have been able to observe the mortality of members of a well defined cohort from birth to old age. The striking stability of the perinatal characteristics of survivors of the cohort at different ages shows that there has not been any substantial differential loss to the cohort as follow up progressed. The associations we have described cannot thus be explained by some sort of selection bias as has been suggested for studies with less complete follow up..$^{11}$

We have shown clearly that the association of birth weight with mortality varies with age. As would be expected, babies weighing less than $3250 \mathrm{~g}$ have particularly high mortality in the first year of life. In childhood, mortality declines progressively across the entire range of birth weight. We have failed to find any other data in the literature from developed countries on this striking association, and we are currently exploring this phenomenon in more detail. In adult life the association of all cause mortality with birth weight is far weaker.

Our data on socioeconomic circumstances come from three points-at birth and at the 1960 and 1970 censuses-and cover many different dimensions of socioeconomic position. With respect to ischaemic heart disease, our results are consistent with those reported from Caerphilly ${ }^{520}$ and the United States nurses health study, ${ }^{6}$ which found that the effect of birth weight on incident coronary disease and myocardial infarction persisted after socioeconomic adjustment. We found a small attenuation of effect after adjustment for socioeconomic circumstances at birth and in adult life, confirming that socioeconomic confounding cannot explain the major part of the association between size at birth and mortality from ischaemic heart disease.

\section{Other studies}

Only three other studies have included information on gestational age. In the Sheffield study this was available for only $822(51 \%)$ men, ${ }^{3}$ while in the United States nurses cohort subjects were asked only whether or not they were born at full term or 2 or more weeks prematurely. ${ }^{6}$ The Finnish ${ }^{7}$ and United States nurses cohorts ${ }^{6}$ both restricted analyses to term births. In contrast, the Uppsala birth cohort study is the first to have complete data on gestational age, which allowed analysis of the effect of growth rate on later mortality as distinct from weight at birth. Our results provide for the first time direct evidence that mortality from ischaemic heart
- Adult mortality from ischaemic heart disease increases as size at birth declines

- This association cannot be explained by artefact including selection bias or socioeconomic confounding

- The effect of size at birth (birth weight, ponderal index) is explained by the more fundamental association of reduced fetal growth rate with increased mortality from ischaemic heart disease

- The relevant determinants of fetal growth rate that drive this association have yet to be identified

disease is associated fetal growth rate (measured as birth weight for gestational age) rather than with size at birth.

The Sheffield ${ }^{3}$ and Helsinki ${ }^{7}$ studies found that ponderal index at birth was inversely associated with risk of ischaemic heart disease. We also found such an inverse association. Our data suggest, however, that this association is largely explained by confounding with birth weight for gestational age as had already been suggested. ${ }^{11}$ This ties in with the perinatal literature that suggests that disproportionality at birth has limited aetiological importance once the severity of intrauterine growth retardation is taken into account..$^{21} 22$

The determinants of variation in fetal growth rate are numerous and include factors such as maternal height, weight, parity, and age as well as paternal height. ${ }^{23}$ How far maternal nutritional status underlies the variations in fetal growth rate observed in our cohort is not possible to assess. In a relatively well nourished population, however, such as our Swedish cohort, maternal nutrition before or during pregnancy is not thought to explain much of the variation in fetal growth rate. ${ }^{23}$

In summary, these data provide the most compelling evidence to date that there is a real association between size at birth and risk of ischaemic heart disease in men that cannot be accounted for by methodological shortcomings or confounding with socioeconomic factors. Most importantly, we have shown for the first time that it is variations in fetal growth rate rather than birth weight or ponderal index that underlie these long term consequences of circumstances in utero.

We thank Lena Nyvall and Charlotte Freiman, whose dedication and hard work in tracing and collecting the obstetric data made a central contribution to this study; Neela Shah, who undertook early analyses of the preliminary data; and Professor Gunilla Lindmark for advice on the use of the obstetric records.

Contributors: The planning of analyses and interpretation of the data was the product of discussions involving all authors, all of whom also commented on drafts of the paper. DAL and PMMcK had the original idea for the study and oversaw its conduct together with HOL and DV. The collection of the obstetric data and the tracing through the parish archives was supervised by RM and UBL. Advice on the use of socioeconomic data at birth was provided by UBL. Advice on obtaining and using the census data was provided by DV. RM and LB undertook the construction of the study database and its cleaning and documentation. IK assisted with the development of systematic checks on the quality of the obstetric and cause of death data and its documentation. Background and interim analyses of results were carried out by IK, LB, and RM. Final analyses and drafting of the original and revised manuscripts were undertaken by DAL, who will act as guarantor. 
Funding: This work was supported through grants from the UK Medical Research Council (grant No 9322050), the Swedish Council for Social Research (grant No 94/0157), and the Swedish Medical Research Council (grant No 5446). During part of her work on this study IK was in receipt of a Royal Society postdoctoral research fellowship.

Conflict of interest: None

1 Barker DJP, Winter PD, Osmond C, Margetts B. Weight in infancy and death from ischaemic heart disease Lancet 1989;ii:577-80.

2 Osmond C, Barker DJP, Winter PD, Fall CHD, Simmonds SJ. Early growth and death from cardiovascular disease in women. BMJ 1993;307: $1519-24$

3 Barker DJP, Osmond C, Simmonds SJ, Wield GA. The relation of small head circumference and thinness at birth to death from cardiovascular disease. $B M J$ 1993;306:422-6.

4 Stein CE, Fall CHD, Kumaran K, Osmond C, Cox V, Barker DJP. Fetal growth and coronary heart disease in South India. Lancet 1996;348 $1269-73$

5 Frankel S, Elwood P, Sweetnam P, Yarnell J, Davey Smith G. Birth weight, body mass index in middle age, and incident coronary heart disease. Lancet 1996;348:1478-80.

6 Rich-Edwards JW, Stampfer MJ, Manson JE, Rosner B, Hankinson SE, Colditz GA, et al. Birth weight and risk of cardiovascular disease in a cohort of women followed up since 1976. BMJ 1997:315:396-400.

7 Forsén TJ, Eriksson JG, Tuomilehto J, Teramo K, Osmond C, Barker DJP. Mother's weight in pregnancy and coronary heart disease in a cohort of Finnish men: follow up study. BMJ 1997;315:837-40.

8 Leon DA, Ben-Shlomo Y. Pre-adult influences on cardiovascular disease and cancer. In: Kuh D, Ben-Shlomo Y, eds. Life course influences on adult disease. Oxford: Oxford University Press, 1997.

9 Eriksson M, Tibblin G, Cnattingius S. Low birth weight and ischaemic heart disease. Lancet 1994;343:731.

10 Paneth N, Susser M. Early origin of coronary heart disease (the "Barker hypothesis"). BMJ 1995;310:411-2.
11 Joseph KS, Kramer MS. Review of the evidence of fetal and early childhood antecedents of adult chronic disease. Epidemiol Rev 1996;18:158-74

12 Ben-Shlomo Y, Davey Smith G. Deprivation in infancy and adult life: which is more important for mortality risk? Lancet 1991;337:530-4.

13 Leon DA, Koupilová I, Lithell HO, Berglund L, Mohsen R, Vågerö D, et al. Failure to realise growth potential in utero and adult obesity in relation to blood pressure in 50 year old Swedish men. BMJ 1996;312:401-6.

14 Lithell HO, McKeigue PM, Berglund L, Mohsen R, Lithell U, Leon DA Relation of size at birth to non-insulin dependent diabetes and insulin concentrations in men aged 50-60 years. BMJ 1996;312:406-10.

15 Koupilová I, Leon DA. Size at birth and mortality from ischaemic heart disease and stroke in Swedish men aged 50-70 years. J Epidemiol Community Health 1996;50:592.

16 Koupilová I, Leon DA, McKeigue PM, Lithell HO. Blood pressure as a potential mediator of the association between low birth weight and high cardiovascular mortality. J Hypertension 1997;15(suppl 4):46.

17 Erikson R, Goldthorpe J. The constant flux. A study of class mobility in indus trial countries. Oxford: Oxford University Press, 1992.

18 Stata Corporation. Stata reference manual:release 5. College Station, Texas: Stata Press, 1997.

19 Koupilová I. Fetal growth, social factors and circulatory diseases. Act Uniw Upsaliensis 1997;698:7-60.

20 Frankel S, Elwood P, Sweetnam P, Yarnell J, Davey Smith G. Birthweight, adult risk factors and incident coronary heart disease: the Caerphilly study. Public Health 1996;110:139-43.

21 Kramer MS, Olivier M, McLean FH, Willis DM, Usher RH. Impact of intrauterine growth retardation and body proportionality on fetal and neonatal outcome. Pediatrics 1990;86:707-13.

22 Vik T, Vatten L, Jacobsen G, Bakketeig LS. Prenatal growth in symmetric and asymmetric small-for-gestational-age infants. Early Hum Dev 1997;48:167-76.

23 Kramer MS. Intrauterine growth and gestational duration determinants. Pediatrics 1987;80:502-11.

24 Susser M. Maternal weight gain, infant birth weight, and diet: causa sequences. Am J Clin Nutr 1991;53:1384-96.

(Accepted 16 April 1998)

\title{
Deprivation and emergency admissions for cancers of colorectum, lung, and breast in south east England: ecological study
}

\author{
Allyson M Pollock, Neil Vickers
}

\begin{abstract}
Objectives: To examine the relation between deprivation and acute emergency admissions for cancers of the colon, rectum, lung, and breast in south east England.

Design: Ecological analysis with data from hospital episode statistics and 1991 census.

Setting: North and South Thames Regional Health Authorities (population about 14 million), divided into 10 aggregations of 31470 census enumeration districts (median population 462).

Subjects: 146639 admissions relating to 76552 patients aged $<100$ years on admission, resident in the Thames regions, admitted between 1 April 1992 and 31 March 1995.

Results: Residents living in deprived areas were more likely to be admitted as emergencies and has ordinary inpatient admissions and less likely to be admitted as day cases. Adjusted odds of ordinary admissions from the most deprived tenth occurring as emergencies (relative to admissions from the most affluent tenth) were 2.29 (95\% confidence interval 2.09 to 2.52 ) for colorectal cancer, 2.20 (1.99 to 2.43) for lung cancer, and 2.41 (2.17 to 2.67) for female breast cancer; adjusted odds of admissions as day cases were 0.70 (0.64 to 0.76$), 0.50$ (0.44 to 0.56 ), and 0.56 (0.50 to
\end{abstract}

0.62), respectively. Patients from deprived areas with lung or breast cancers were less likely to be recorded as having surgical interventions. Adjusted odds of patients from the most deprived tenth receiving surgery were 0.88 ( 0.78 to 1.00$), 0.58$ (0.48 to 0.70$)$, and 0.63 (0.56 to 0.71 ), respectively. Admissions for colorectal cancer from the most deprived areas were less likely to be to hospitals admitting 100 or more new patients a year; the opposite held true for breast cancer admissions. No association was found for lung cancer admissions.

Conclusions: Earlier diagnostic and referral procedures in primary care in deprived areas are required if there are to be significant reductions in mortality from these cancers. A national information strategy is required to ensure the continued availability of population based data on NHS patients and to mandate standardised datasets from the private sector. Rationalisation of acute services, hospital mergers, and plans for bed closures must take into account the increased healthcare needs and inequities in access to treatment and care of residents in areas with high levels of deprivation. Health authorities and primary care groups should re-examine their purchasing intentions, service reviews, and monitoring arrangements in the light of these findings.
Department of

Public Health

Sciences,

St George's

Hospital Medical

School, London

SW17 0RE

Allyson M Pollock, senior lecturer in

public health medicine

Neil Vickers,

research assistant

Correspondence to: Dr Pollock, School

of Public Policy,

University College

London, London

WC1E 7HN

BMJ 1998;317:245-52 